\title{
Wet packing of blended fine and coarse aggregate
}

\author{
A. K. H. Kwan • L. G. Li • W. W. S. Fung
}

Received: 31 December 2010/ Accepted: 18 October 2011/Published online: 8 November 2011

(C) The Author(s) 2011. This article is published with open access at Springerlink.com

\begin{abstract}
All codified methods for measuring the packing density of aggregate are carried out under dry condition. However, these dry packing methods do not account for the effect of water in the concrete mix. In a previous study, a wet packing method for measuring the packing density of fine aggregate under wet condition has been developed and it was found that the packing density of fine aggregate can be substantially higher under wet condition than dry condition. Nevertheless, many researchers still believe that for coarse aggregate, it does not matter much whether the packing density is measured under dry or wet condition. In this study, the wet packing method was extended to measure the packing density of coarse aggregate and blended fine and coarse aggregate. The results revealed that whilst the packing density of coarse aggregate is only slightly higher under wet condition than dry condition, the packing density of blended fine and coarse aggregate is highly dependent on whether the aggregate is dry or wet. Hence, when measuring the packing density of blended aggregate, the wet packing method should always be used.
\end{abstract}

Keywords Aggregate - Concrete mix design . Packing density

A. K. H. Kwan $(\bowtie) \cdot$ L. G. Li · W. W. S. Fung Department of Civil Engineering, The University of Hong Kong, Hong Kong, China e-mail: khkwan@hku.hk

\section{Introduction}

The packing density of particles, which is defined as the ratio of the solid volume of the particles to the bulk volume occupied by the particles, is a fundamental parameter governing the properties of many materials made from particles such as ceramics [1] and is thus an important topic in powder science and technology [2]. Since concrete is also made largely of particles, its properties are greatly affected by the packing density of its solid ingredients. Hence, research on the packing density of the solid ingredients, including the aggregate particles and cementitious materials, can help to improve our understanding of the behavior of concrete.

Early in 1960s, Powers [3] postulated that it is the excess paste (the paste in excess of the amount needed to fill the voids between the aggregate particles) that lubricates the concrete mix. Therefore, at the same paste volume, a higher packing density of the aggregate would increase the amount of excess paste and lead to a higher workability. Alternatively, at the same workability requirement, a higher packing density of the aggregate would allow the use of a smaller paste volume to increase the dimensional stability, and reduce the cement consumption, cost of production and carbon footprint of the concrete.

Following the geometric similarity principle, it may be postulated that it is the excess water (the water in excess of the amount needed to fill the voids between the cementitious materials) that lubricates the cement 
paste. Therefore, a higher packing density of the cementitious materials would at the same water content lead to a higher flowability of the cement paste or at the same flowability requirement allow the use of a lower water/cementitious materials (W/CM) ratio to increase the strength and durability. For instance, in the 1990s, De Larrard and Sedran [4] and Lange et al. [5] maximized the packing density of the cementitious materials to reduce the W/CM ratio and thus improved the strength and durability of the mortar produced. In 2008, Kwan and Wong [6] demonstrated by packing density and flowability measurements that blending of cement with appropriate proportions of pulverized fuel ash and condensed silica fume can increase the packing density of the cementitious materials and thereby increase the flowability of the cement paste formed.

Rather than considering the aggregate or the cementitious materials separately, it has also been suggested that when maximizing the packing density, all the solid particles in the concrete mix should be considered concurrently. In 1996, Sedran et al. [7] proposed to maximize the packing density of the entire granular skeleton, including the aggregate and the cementitious materials, for the production of selfconsolidating concrete (SCC). Their rationale was simply that the excess water (in this context, the water in excess of the amount needed to fill the voids between all solid particles) lubricates not only the cement paste but also the whole concrete mix. Later, in 2005, Brouwers and Radix [8] advocated that whilst the packing of the aggregate plays a major role, the packing of all solid particles in the concrete mix should be the basis for the mix design of SCC.

Meanwhile, theoretical packing models have been developed for modeling the packing of multi-blended solid particles (two or more size classes of particles blended together). These are useful tools for predicting the packing densities of cement paste, mortar and concrete (herein, the packing density of a solid-water mixture means the packing density of the solid particles in the mixture), and for packing density optimization. In 1930, Westman and Hugill [9] established the linear packing theory, which has been used as the basis for the development of several packing models, such as those developed by Yu et al. [10] and by De Larrard [11]. There are also packing models, which consider successively double-blended solid particles (two size classes of particles blended together) to evaluate the packing density of multiblended solid particles, such as those developed by Tourfar as cited in Ref. [12] and by Dewar [13]. More recently, Wong and Kwan [14] and Kwan and Fung [15] compared their experimentally measured packing density results with the theoretically predicted results by existing packing models to counter check the accuracies of the experimental results and the applicability of the existing packing models. Apart from packing models, computer simulations have also been developed to study the packing of particles [16-18].

However, the packing densities of cement paste, mortar and concrete have rarely been directly measured. For fine and coarse aggregates, there are codified test methods for measuring the packing density under dry condition [19-22], but for cementitious materials, there is up to now no generally accepted test method for measuring the packing density under dry or wet condition. Besides, it should be noted that the dry packing methods have the major problems that the measured packing density is sensitive to the amount of compaction applied [23] and that they do not include the possible effect of water. These problems are more serious when finer particles are dealt with because the inter-particles forces causing agglomeration and loose packing $[24,25]$ are then comparatively larger. Hence, the dry packing methods are not applicable to cementitious materials. To resolve these problems, Wong and Kwan [26] have, in 2008, developed a wet packing method for measuring the packing density of cementitious materials under wet condition. This method has been employed to study the effect of packing density on rheology of cement paste $[27,28]$. Later, it was extended for application to fine aggregate [29] and employed to study the effect of packing density on rheology of mortar [30, 31].

It is a common belief that the effect of water on the packing density of aggregate is not significant because the aggregate particles are relatively large. However, this belief has never been proven by actual packing density measurements under both dry and wet conditions. Recently, in the course of research on the wet packing of fine aggregate [29], it was found that the packing density of fine aggregate can be $24 \%$ higher under wet condition than dry condition. Hence, the effect of water on the packing density of fine aggregate is not small at all.

In this research, the wet packing method was extended to measure the packing densities of coarse 
aggregate and blended fine and coarse aggregate under wet condition. Using this wet packing method, the wet packing densities of coarse aggregate and blended fine and coarse aggregate were measured with or without compaction applied and with or without superplasticizer added. The wet packing density results were compared with the respective dry packing density results obtained by the conventional dry packing method to study the effect of water. Furthermore, the effects of compaction, superplasticizer, blending of different size aggregates together and particle size ratio were also investigated. This is an important step for further development of the wet packing method, which is an indispensable tool for studying the effects of packing density and for incorporating the concept of packing into mix design methods for high-performance concrete.

\section{Definition of terms}

For clarification, the terms describing the packing of a particle system are first defined herein. In the bulk volume of solid particles, the interstitial space between the particles can be described by either the voids content or the voids ratio. The voids content (denoted by $\varepsilon$ ) is defined as the ratio of the volume of voids to the bulk volume of the particles while the voids ratio (denoted by $u$ ) is defined as the ratio of the volume of voids to the solid volume of the particles. They are inter-related by:

$\varepsilon=\frac{u}{1+u}$

Depending on the moisture condition, the voids may be filled with water or air or both. The water content (denoted by $\varepsilon_{\mathrm{W}}$ ) is defined as the ratio of the volume of water to the bulk volume of the particles and the water ratio (denoted by $u_{\mathrm{w}}$ ) is defined as the ratio of the volume of water to the solid volume of the particles. Similarly, the air content (denoted by $\varepsilon_{\mathrm{a}}$ ) is defined as the ratio of the volume of air to the bulk volume of the particles and the air ratio (denoted by $u_{\mathrm{a}}$ ) is defined as the ratio of the volume of air to the solid volume of the particles. These terms are related to each other by:

$u=u_{\mathrm{w}}+u_{\mathrm{a}}$ $\varepsilon=\varepsilon_{\mathrm{w}}+\varepsilon_{\mathrm{a}}$

On the other hand, the solid concentration (denoted by $\phi$ ) is defined as the ratio of the solid volume of the particles to the bulk volume of the particles. It is given by:

$\phi=1-\varepsilon=\frac{1}{1+u}$

\section{Testing program and methods}

The purposes of the testing program were to measure and compare the packing densities of non-blended fine aggregate, non-blended coarse aggregate and blended fine plus coarse aggregate under different conditions. Four size classes of aggregate, including one size class of fine aggregate, named as F1, and three size classes of coarse aggregate, named as $\mathrm{C} 1, \mathrm{C} 2$ and $\mathrm{C} 3$, were used for the packing density tests. F1 was a fine aggregate with particle size smaller than $1.18 \mathrm{~mm}$ (all passed through $1.18 \mathrm{~mm}$ sieve), whereas $\mathrm{C} 1, \mathrm{C} 2$ and $\mathrm{C} 3$ were coarse aggregates with particle sizes ranging from 5 to $10 \mathrm{~mm}$ (passed through $10 \mathrm{~mm}$ sieve but retained on $5 \mathrm{~mm}$ sieve), from 10 to $14 \mathrm{~mm}$ (passed through $14 \mathrm{~mm}$ sieve but retained on $10 \mathrm{~mm}$ sieve) and from 14 to $20 \mathrm{~mm}$ (passed through $20 \mathrm{~mm}$ sieve but retained on $14 \mathrm{~mm}$ sieve), respectively, as depicted in Table 1. In order to investigate the effects of water, compaction and superplasticizer (SP), a total of six testing conditions were applied, as summarized in Table 2 and explained later.

From each size class, a non-blended aggregate sample was taken for packing density tests, as listed in the first column of Table 3. Furthermore, blended aggregate samples were produced by blending different proportions of fine aggregate (F1) and coarse aggregate $(\mathrm{C} 1, \mathrm{C} 2$ or $\mathrm{C} 3)$ together. The mix

Table 1 Four size classes of crushed rock aggregate

\begin{tabular}{llll}
\hline $\begin{array}{l}\text { Size } \\
\text { class }\end{array}$ & \begin{tabular}{l} 
Sieve size range \\
\cline { 2 - 3 }
\end{tabular} & $\begin{array}{l}\text { Lower sieve size } \\
\text { (sieve retained on) } \\
(\mathrm{mm})\end{array}$ & $\begin{array}{l}\text { Upper sieve size } \\
\text { (sieve passed } \\
\text { particle } \\
\text { size }(\mathrm{mm})\end{array}$ \\
\hline F1 & - & 1.18 & \\
$\mathrm{C} 1$ & 5 & 10 & 0.31 \\
$\mathrm{C} 2$ & 10 & 14 & 7.07 \\
$\mathrm{C} 3$ & 14 & 20 & 11.83 \\
\hline
\end{tabular}


Table 2 Testing conditions

\begin{tabular}{llll}
\hline $\begin{array}{l}\text { Testing } \\
\text { condition }\end{array}$ & Water & Compaction & Superplasticizer \\
\hline D1 & Dry & $\begin{array}{c}\text { Uncompacted } \\
\text { Compacted using a } \\
\text { tamping rod }\end{array}$ & Nil \\
D2 & & Uncompacted & Nil \\
W1 & Wet & $\begin{array}{c}\text { Compacted using a } \\
\text { tamping rod }\end{array}$ & Nil \\
W2 & & Uncompacted & Added \\
W3 & & Compacted using a & Added \\
W4 & & tamping rod & \\
\hline
\end{tabular}

proportions of a blended aggregate sample were defined in terms of the fine to total aggregate $(\mathrm{F} / \mathrm{T})$ ratio, which varied from 0.00 (no fine aggregate) to 1.00 (all fine aggregate) in steps of 0.05 or 0.10 . For easy identification, each blended aggregate sample was assigned a sample number in the form of $X+Y-Z$, in which $X$ denotes the size class of fine aggregate (F1), $Y$ denotes the size class of coarse aggregate $(\mathrm{C} 1, \mathrm{C} 2$ or $\mathrm{C} 3)$ and $Z$ denotes the $\mathrm{F} / \mathrm{T}$ ratio. In total, 36 blended aggregate samples were produced for packing density tests, as listed in the first column of Table 4.

\subsection{Dry packing tests}

The test methods stipulated in British Standard BS 812: Part 2: 1995 [20] for measuring uncompacted and compacted packing densities of aggregate were adopted. Herein, the testing conditions under which the uncompacted and compacted packing densities were determined are designated as D1 and D2, respectively (see Table 2). For testing under condition D1, the aggregate sample was filled into the container for packing density measurement without applying any compaction. For testing under condition D2, the aggregate sample was filled into the container in three equal portions and each time after filling a one-third portion, the aggregate in the container was compacted by applying 20 compactive blows with a metal tamping rod. In this research, for each non-blended aggregate sample, the sample was first used for measuring the uncompacted packing density under condition D1, and then remixed and reused for measuring the compacted packing density under condition D2. This was to study the effect of compaction on the dry packing density. For each blended aggregate sample, only the uncompacted packing density under condition D1 was measured because the tests on blended aggregate samples were mainly to study the effects of water and SP, not compaction.

\subsection{Wet packing tests}

The test method employed was essentially the same as the wet packing method developed previously for fine aggregate by the authors' research team [29]. It involved the following steps: mixing with water and SP (if any), filling into a container, compaction (if any) and bulk density measurement. First, the aggregate sample was thoroughly mixed with predetermined amounts of water and SP (if any). Then, the mixture was filled into the container. During filling, compaction was applied to the mixture, if required. Finally, the bulk density of the mixture was measured to evaluate the solid concentration of the particles. The container used was the same as that stipulated in BS 812: Part 2: 1995 [20] for dry packing tests.

Four different testing conditions, namely, W1, W2, W3 and W4 (see Table 2), have been applied during the wet packing tests. Under conditions W1 and W2, no SP was added, while under conditions $\mathrm{W} 3$ and $\mathrm{W} 4$, $\mathrm{SP}$ was added to the aggregate-water mixture. On the other hand, under conditions $\mathrm{W} 1$ and $\mathrm{W} 3$, no

Table 3 Packing density results of non-blended aggregates

\begin{tabular}{lllllll}
\hline Size class & \multicolumn{6}{l}{ Packing density under each testing condition } \\
\cline { 2 - 7 } & D1 & D2 & W1 & W2 & W3 & W4 \\
\hline F1 & 0.542 & 0.634 & 0.641 & 0.672 & 0.652 & 0.681 \\
C1 & 0.487 & 0.543 & 0.502 & 0.561 & 0.505 & 0.563 \\
C2 & 0.501 & 0.546 & 0.510 & 0.557 & 0.511 & 0.559 \\
C3 & 0.515 & 0.551 & 0.524 & 0.553 & 0.524 & 0.554 \\
\hline
\end{tabular}


Table 4 Packing density results of blended aggregates

\begin{tabular}{|c|c|c|c|c|c|c|}
\hline \multirow[t]{2}{*}{ Sample number } & \multirow{2}{*}{$\begin{array}{l}\mathrm{F} / \mathrm{T} \\
\text { ratio }\end{array}$} & \multicolumn{3}{|c|}{ Packing density under each testing condition } & \multirow{2}{*}{$\begin{array}{l}\text { Increase in packing } \\
\text { density due to water }(\%)\end{array}$} & \multirow{2}{*}{$\begin{array}{l}\text { Increase in packing } \\
\text { density due to SP (\%) }\end{array}$} \\
\hline & & D1 & W1 & W3 & & \\
\hline $\mathrm{F} 1+\mathrm{C} 1-0.00$ & 0.00 & 0.487 & 0.502 & 0.505 & 3.1 & 0.6 \\
\hline $\mathrm{F} 1+\mathrm{C} 1-0.10$ & 0.10 & 0.545 & 0.553 & 0.554 & 1.5 & 0.2 \\
\hline $\mathrm{F} 1+\mathrm{C} 1-0.20$ & 0.20 & 0.591 & 0.603 & 0.606 & 2.0 & 0.5 \\
\hline $\mathrm{F} 1+\mathrm{C} 1-0.30$ & 0.30 & 0.632 & 0.668 & 0.670 & 5.7 & 0.3 \\
\hline $\mathrm{F} 1+\mathrm{C} 1-0.35$ & 0.35 & 0.643 & 0.700 & 0.702 & 8.9 & 0.3 \\
\hline $\mathrm{F} 1+\mathrm{C} 1-0.40$ & 0.40 & 0.655 & 0.721 & 0.721 & 10.1 & 0.0 \\
\hline $\mathrm{F} 1+\mathrm{C} 1-0.45$ & 0.45 & 0.667 & 0.740 & 0.742 & 10.9 & 0.3 \\
\hline $\mathrm{F} 1+\mathrm{C} 1-0.50$ & 0.50 & 0.672 & 0.745 & 0.749 & 10.9 & 0.5 \\
\hline $\mathrm{F} 1+\mathrm{C} 1-0.55$ & 0.55 & 0.682 & 0.727 & 0.734 & 6.6 & 1.0 \\
\hline $\mathrm{F} 1+\mathrm{C} 1-0.60$ & 0.60 & 0.677 & 0.713 & 0.722 & 5.3 & 1.3 \\
\hline $\mathrm{F} 1+\mathrm{C} 1-0.80$ & 0.80 & 0.623 & 0.675 & 0.685 & 8.3 & 1.5 \\
\hline $\mathrm{F} 1+\mathrm{C} 1-1.00$ & 1.00 & 0.542 & 0.641 & 0.652 & 18.3 & 1.7 \\
\hline $\mathrm{F} 1+\mathrm{C} 2-0.00$ & 0.00 & 0.501 & 0.510 & 0.511 & 1.8 & 0.2 \\
\hline $\mathrm{F} 1+\mathrm{C} 2-0.10$ & 0.10 & 0.594 & 0.609 & 0.610 & 2.5 & 0.2 \\
\hline $\mathrm{F} 1+\mathrm{C} 2-0.20$ & 0.20 & 0.643 & 0.671 & 0.673 & 4.4 & 0.3 \\
\hline $\mathrm{F} 1+\mathrm{C} 2-0.30$ & 0.30 & 0.705 & 0.758 & 0.763 & 7.5 & 0.7 \\
\hline $\mathrm{F} 1+\mathrm{C} 2-0.35$ & 0.35 & 0.719 & 0.773 & 0.777 & 7.5 & 0.5 \\
\hline $\mathrm{F} 1+\mathrm{C} 2-0.40$ & 0.40 & 0.723 & 0.764 & 0.769 & 5.7 & 0.7 \\
\hline $\mathrm{F} 1+\mathrm{C} 2-0.45$ & 0.45 & 0.720 & 0.757 & 0.763 & 5.1 & 0.8 \\
\hline $\mathrm{F} 1+\mathrm{C} 2-0.50$ & 0.50 & 0.710 & 0.751 & 0.758 & 5.8 & 0.9 \\
\hline $\mathrm{F} 1+\mathrm{C} 2-0.55$ & 0.55 & 0.705 & 0.738 & 0.745 & 4.7 & 0.9 \\
\hline $\mathrm{F} 1+\mathrm{C} 2-0.60$ & 0.60 & 0.694 & 0.725 & 0.732 & 4.5 & 1.0 \\
\hline $\mathrm{F} 1+\mathrm{C} 2-0.80$ & 0.80 & 0.631 & 0.677 & 0.685 & 7.3 & 1.2 \\
\hline $\mathrm{F} 1+\mathrm{C} 2-1.00$ & 1.00 & 0.542 & 0.641 & 0.652 & 18.3 & 1.7 \\
\hline $\mathrm{F} 1+\mathrm{C} 3-0.00$ & 0.00 & 0.515 & 0.524 & 0.524 & 1.7 & 0.0 \\
\hline $\mathrm{F} 1+\mathrm{C} 3-0.10$ & 0.10 & 0.607 & 0.619 & 0.620 & 2.0 & 0.2 \\
\hline $\mathrm{F} 1+\mathrm{C} 3-0.20$ & 0.20 & 0.673 & 0.700 & 0.702 & 4.0 & 0.3 \\
\hline $\mathrm{F} 1+\mathrm{C} 3-0.30$ & 0.30 & 0.743 & 0.787 & 0.792 & 5.9 & 0.6 \\
\hline $\mathrm{F} 1+\mathrm{C} 3-0.35$ & 0.35 & 0.751 & 0.805 & 0.811 & 7.2 & 0.7 \\
\hline $\mathrm{F} 1+\mathrm{C} 3-0.40$ & 0.40 & 0.754 & 0.786 & 0.791 & 4.2 & 0.6 \\
\hline $\mathrm{F} 1+\mathrm{C} 3-0.45$ & 0.45 & 0.744 & 0.775 & 0.779 & 4.2 & 0.5 \\
\hline $\mathrm{F} 1+\mathrm{C} 3-0.50$ & 0.50 & 0.739 & 0.760 & 0.765 & 2.8 & 0.7 \\
\hline $\mathrm{F} 1+\mathrm{C} 3-0.55$ & 0.55 & 0.721 & 0.744 & 0.751 & 3.2 & 0.9 \\
\hline $\mathrm{F} 1+\mathrm{C} 3-0.60$ & 0.60 & 0.701 & 0.732 & 0.739 & 4.4 & 1.0 \\
\hline $\mathrm{F} 1+\mathrm{C} 3-0.80$ & 0.80 & 0.637 & 0.680 & 0.687 & 6.8 & 1.0 \\
\hline $\mathrm{F} 1+\mathrm{C} 3-1.00$ & 1.00 & 0.542 & 0.641 & 0.652 & 18.3 & 1.7 \\
\hline
\end{tabular}

compaction was applied, while under conditions W2 and $\mathrm{W} 4$, compaction was applied to the mixture in the container by applying 20 compactive blows with a metal tamping rod every time after filling a one-third portion into the container (same as that applied under condition D2 during the dry packing tests). For the non-blended aggregate samples, each sample was subjected to the wet packing tests under all the four conditions W1, W2, W3 and W4. This was to study the effects of compaction and SP on the wet packing density. For the blended aggregate samples, each sample was subjected to the wet packing tests only 
under the conditions W1 and W3 because the tests on blended aggregate samples were mainly to study the effects of water and SP, not compaction.

Under wet condition, the spatial distribution of solid particles is dependent on the water/solid ratio by volume, which is abbreviated herein as W/S ratio (note that the W/S ratio is the same as the water ratio). At a W/S ratio higher than that at saturation state, a suspension is formed and the particles are dispersed in the water, causing the solid concentration to decrease as the W/S ratio increases. On the other hand, at a W/S ratio lower than that at saturation state, the water added is not sufficient to fill up the voids. As a result, air is trapped inside the voids and water bridges are formed between the particles, causing the solid concentration to decrease as the W/S ratio decreases. Hence, there is an optimum W/S ratio, called basic water ratio, at which the solid concentration reaches its maximum value and the particles are most closely packed. The maximum solid concentration so achieved is taken as the wet packing density. In order to determine the wet packing density, therefore, it is necessary to find out the solid concentrations at different W/S ratios over a range wide enough to cover the optimum W/S ratio. With no previous data to help decide on an appropriate range, it is suggested to start at a low W/S ratio of 0.2 for the first test and then successively increase the W/S ratio for further tests.

The test procedures of the wet packing test are described below:

(a) Set the W/S ratio at which the test is to be carried out. Weigh the required quantities of aggregate, water and SP (if any).

(b) Put the aggregate into the mixing bowl and premix the aggregate for $2 \mathrm{~min}$ to ensure uniformity of the aggregate sample.

(c) Add the water and SP (if any) into the mixing bowl and run the mixer for $3 \mathrm{~min}$.

(d) Transfer the mixture to the container for bulk density measurement and fill the container layer by layer. If compaction is to be applied, apply compaction every time after filling a one-third portion into the container.

(e) Fill the container to slight excess. Remove the excess with a straight edge and weigh the amount of mixture in the container to determine the bulk density. (f) Pour the mixture into the mixing bowl and run the mixer for $3 \mathrm{~min}$. Then repeat steps (d) and (e) for another bulk density measurement. Calculate the mean of the two bulk density measurements as the bulk density result.

(g) Repeat steps (a) to (f) at successively higher W/S ratios by adding more water until the maximum solid concentration has been found.

From the bulk volume of the mixture (denoted by $V$ ), which is the same as the volume of the container, and the solid volume of the aggregate (denoted by $V_{\mathrm{s}}$ ), which can be determined from the W/S ratio and the weight of the mixture, the voids ratio $u$ and solid concentration $\phi$ can be determined as:

$u=\frac{V-V_{\mathrm{s}}}{V_{\mathrm{s}}}$

$\phi=\frac{V_{\mathrm{s}}}{V}$

Plotting the voids ratio $u$ and solid concentration $\phi$ against the $\mathrm{W} / \mathrm{S}$ ratio, the minimum voids ratio and maximum solid concentration can be determined.

\section{Materials}

Both the fine and coarse aggregates were obtained from crushed granite rock. Only one size class of fine aggregate with a maximum size of $1.18 \mathrm{~mm}$ was used. This size class, denoted by F1, was obtained by sieving crushed rock fine through the $1.18 \mathrm{~mm}$ sieve and discarding the portion retained on the $1.18 \mathrm{~mm}$ sieve. The particle size distribution of F1, measured using a laser diffraction method, is presented in Fig. 1. From the particle size distribution, the mean particle size of F1 has been calculated as $0.31 \mathrm{~mm}$. On the other hand, three size classes of coarse aggregates, denoted by $\mathrm{C} 1$, $\mathrm{C} 2$ and C3, were used. They were obtained by sieving coarse aggregate through the 20,14, 10 and $5 \mathrm{~mm}$ sieves. After sieving, the aggregate particles retained on the 5, 10 and $14 \mathrm{~mm}$ sieves were collected to become C1, C2 and C3, respectively. Since each size class falls within a narrow size range, each of $\mathrm{C} 1, \mathrm{C} 2$ and C3 may be regarded as single-sized having a mean size equal to the geometric mean of the lower and upper sieve sizes, as presented in Table 1.

The solid densities of $\mathrm{F} 1, \mathrm{C} 1, \mathrm{C} 2$ and $\mathrm{C} 3$ under saturated and surface dry condition were measured to 


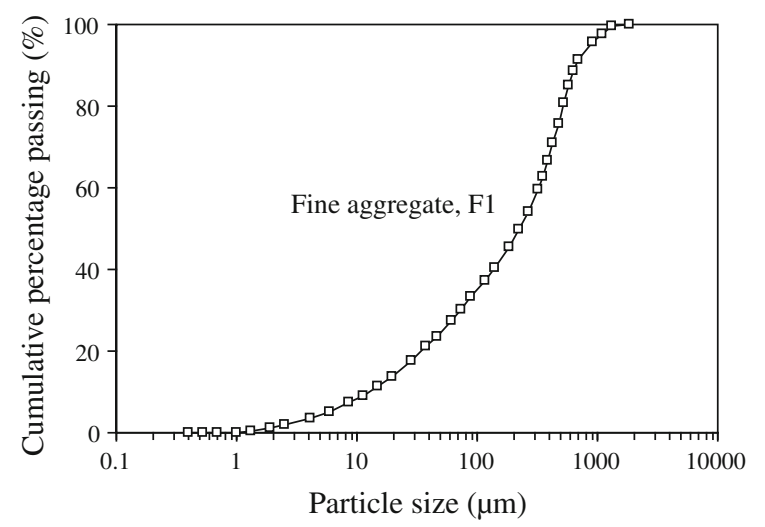

Fig. 1 Particle size distribution of fine aggregate F1

be $2660,2531,2579$ and $2599 \mathrm{~kg} / \mathrm{m}^{3}$, respectively. Furthermore, the moisture contents of F1, C1, C2 and $\mathrm{C} 3$ were measured as $0.45 \%, 0.23 \%, 0.35 \%$ and $0.37 \%$, respectively, while the water absorptions of $\mathrm{F} 1, \mathrm{C} 1, \mathrm{C} 2$ and $\mathrm{C} 3$ were measured as $1.02 \%, 0.81 \%, 0.67 \%$ and $0.52 \%$, respectively. All these measurements were carried out in accordance with BS 812: Part 2: 1995 [20]. The above moisture content and water absorption were taken into account in the calculation of the test results. From the particle size distribution and the mean sizes, the specific surface areas of $\mathrm{F} 1, \mathrm{C} 1, \mathrm{C} 2$ and C3 were calculated as $2.12 \times 10^{5}, 755,507$ and $359 \mathrm{~m}^{2} / \mathrm{m}^{3}$, respectively.

The SP added was a third-generation polycarboxylate-based admixture with a solid content of $20 \%$ and a relative density of 1.03 . According to the supplier, the normal dosage of this SP in terms of liquid mass should be $0.5-3.0 \%$ of the cement content by mass. Since SP actually acts on the particle surfaces, the SP dosage should better be designed according to the total surface area of the solid particles in the solid-water mixture. Assuming that cement has a typical specific surface area of $1.10 \times 10^{6} \mathrm{~m}^{2} / \mathrm{m}^{3}$ and a typical solid density of $3100 \mathrm{~kg} / \mathrm{m}^{3}$, a typical SP dosage of $1.0 \%$ of the cement content by mass corresponds to $2.82 \times$ $10^{-5} \mathrm{~kg} / \mathrm{m}^{2}$ of SP per surface area of the solid particles. As only aggregate was dealt with, the SP dosage used in this research was set simply as $2.82 \times 10^{-5} \mathrm{~kg} / \mathrm{m}^{2}$ of SP per surface area of aggregate. For each aggregate sample, the total surface area of the aggregate was first calculated and then the SP dosage was determined by multiplying the total surface area with the above SP dosage per surface area.

\section{Results and discussions}

\subsection{Variations of voids ratio and solid concentration with $\mathrm{W} / \mathrm{S}$ ratio}

For illustration, the variations of the voids ratio $u$ and solid concentration $\phi$ with the W/S ratio obtained during the wet packing test of a typical aggregate sample F1 + C3-0.60 are plotted in Fig. 2. From the curves plotted, it can be seen that there was an optimum W/S ratio, called the basic water ratio, at which the voids ratio reached a minimum value and the solid concentration reached a maximum value. Similar variations of the voids ratio and solid concentration with the W/S ratio were obtained for all the other aggregate samples tested. In each case, the maximum solid concentration so determined was taken as the packing density of the aggregate sample tested. However, it should be noted that the basic water ratio is not necessarily equal to the minimum voids ratio because there may be entrapped air causing the air ratio to be non-zero when minimum voids ratio occurs. Hence, the basic water ratio should not be mistaken as the minimum amount of water needed to fill up the voids.

\subsection{Packing density results of non-blended aggregate}

The packing density results of the non-blended aggregates $\mathrm{F} 1, \mathrm{C} 1, \mathrm{C} 2$ and $\mathrm{C} 3$ under the testing conditions D1, D2, W1, W2, W3 and W4 are presented in Table 3. From the table, it is obvious that the packing density of the fine aggregate $\mathrm{F} 1$ was within $0.542-0.681$, the packing density of the coarse aggregate $\mathrm{C} 1$ was within $0.487-0.563$, the packing density of the coarse aggregate C2 was within 0.501-0.559, and the packing density of the coarse aggregate $\mathrm{C} 3$ was within $0.515-0.554$. On the whole, the packing density of the fine aggregate was higher than the packing density of every coarse aggregate under any testing condition. This was because the fine aggregate has a much wider size range than every coarse aggregate. From these results, the effects of water, compaction and SP on packing density can be evaluated, as presented in the following paragraphs.

Comparing the packing density results under the wet conditions $\mathrm{W} 1$ and $\mathrm{W} 2$ to those under the dry 


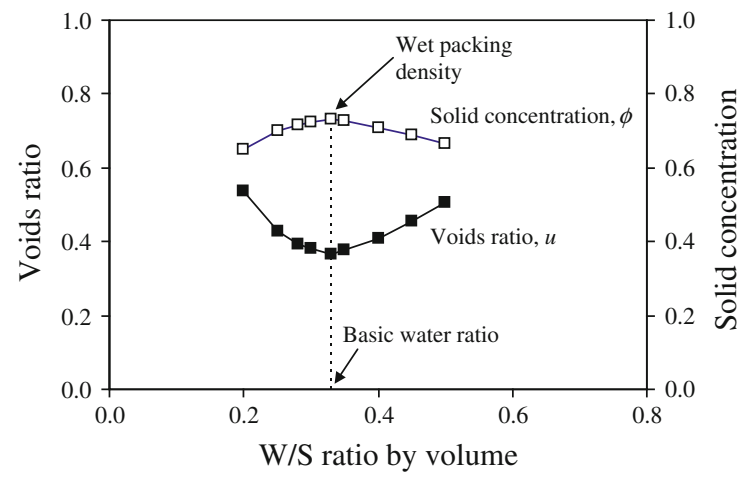

Fig. 2 Wet packing test results for $\mathrm{F} 1+\mathrm{C} 3-0.60$ under condition $\mathrm{W} 1$

conditions D1 and D2, it can be seen that regardless of whether compaction was applied and whether the aggregate was fine or coarse, the packing density of the aggregate was generally higher under wet condition than dry condition. Without compaction applied, the presence of water increased the packing density of $\mathrm{F} 1, \mathrm{C} 1, \mathrm{C} 2$ and $\mathrm{C} 3$ by $18.3 \%, 3.1 \%, 1.8 \%$ and $1.7 \%$, respectively. With compaction applied, the presence of water increased the packing density of $\mathrm{F} 1, \mathrm{C} 1, \mathrm{C} 2$ and $\mathrm{C} 3$ by $6.0 \%, 3.3 \%, 2.0 \%$ and $0.4 \%$, respectively. Evidently, the presence of water has very large effect on the packing density of fine aggregate but little effect on the packing density of coarse aggregate. Relatively, the effect of water on the packing density of fine aggregate was larger under the uncompacted condition.

Comparing the packing density results under the compacted conditions D2 and W2 to those under the uncompacted conditions D1 and W1, it can be seen that regardless of the water condition and whether the aggregate was fine or coarse, the packing density of the aggregate was generally higher with compaction applied. Under dry condition, the compaction increased the packing density of $\mathrm{F} 1, \mathrm{C} 1, \mathrm{C} 2$ and $\mathrm{C} 3$ by $17.0 \%, 11.5 \%, 9.0 \%$ and $7.0 \%$, respectively. Under wet condition, the compaction increased the packing density of $\mathrm{F} 1, \mathrm{C} 1, \mathrm{C} 2$ and $\mathrm{C} 3$ by $4.8 \%, 11.8 \%, 9.2 \%$ and $5.5 \%$, respectively. Whilst the dry packing density of fine aggregate was quite sensitive to compaction, the wet packing density of fine aggregate was less sensitive to compaction. This was because under wet condition, the fine aggregate already achieved a fairly high packing density even without compaction and thus further increase in packing density due to compaction was limited.
Comparing the packing density results under the conditions W3 and W4 to those under the conditions $\mathrm{W} 1$ and $\mathrm{W} 2$, it can be seen that regardless of whether compaction was applied and whether the aggregate was fine or coarse, the packing density of the aggregate was generally higher with SP added. Without compaction applied, the addition of SP increased the packing density of $\mathrm{F} 1, \mathrm{C} 1, \mathrm{C} 2$ and $\mathrm{C} 3$ by $1.7 \%, 0.6 \%, 0.2 \%$ and $0.0 \%$, respectively. With compaction applied, the addition of SP increased the packing density of $\mathrm{F} 1, \mathrm{C} 1, \mathrm{C} 2$ and $\mathrm{C} 3$ by $1.3 \%, 0.4 \%$, $0.4 \%$ and $0.2 \%$, respectively. Overall, the addition of SP has a slight beneficial effect on the packing density of fine aggregate but very little effect on the packing density of coarse aggregate.

\subsection{Packing density results of blended aggregate}

The packing density results of the blended aggregates $\mathrm{F} 1+\mathrm{C} 1, \mathrm{~F} 1+\mathrm{C} 2$ and $\mathrm{F} 1+\mathrm{C} 3$ with different $\mathrm{F} / \mathrm{T}$ ratios under the testing conditions $\mathrm{D} 1, \mathrm{~W} 1$ and $\mathrm{W} 3$ are presented in Table 4 and plotted against the F/T ratio in Figs. 3, 4 and 5. These results revealed that under dry condition, the packing density of the blended aggregate was within $0.487-0.754$. With water but no SP added, the packing density was increased to within $0.502-0.805$ while with both water and SP added, the packing density was further increased to within 0.505-0.811. Hence, both the water and SP added have some effects on the packing density of blended aggregate.

Comparing the packing density results under the condition W1 to those under the condition D1, it can be seen that for all blended aggregate samples, regardless of the F/T ratio, the wet packing density was significantly higher than the corresponding dry packing density. Such effect of water may be studied in terms of the increase in packing density due to the addition of water, as tabulated in the sixth column of Table 4. From the tabulated values, it is evident that the effect of water varied from smaller than $4 \%$ when the $\mathrm{F} / \mathrm{T}$ ratio was relatively low and close to 0 to as large as $18 \%$ when the F/T ratio was relatively high and close to 1 . From the curves plotted in Figs. 3, 4 and 5 for the packing densities under conditions D1 and $\mathrm{W} 1$, it is also evident that the presence of water would affect the optimum $\mathrm{F} / \mathrm{T}$ ratio at which the maximum packing density would be achieved. Generally, the optimum F/T ratio for maximum packing 


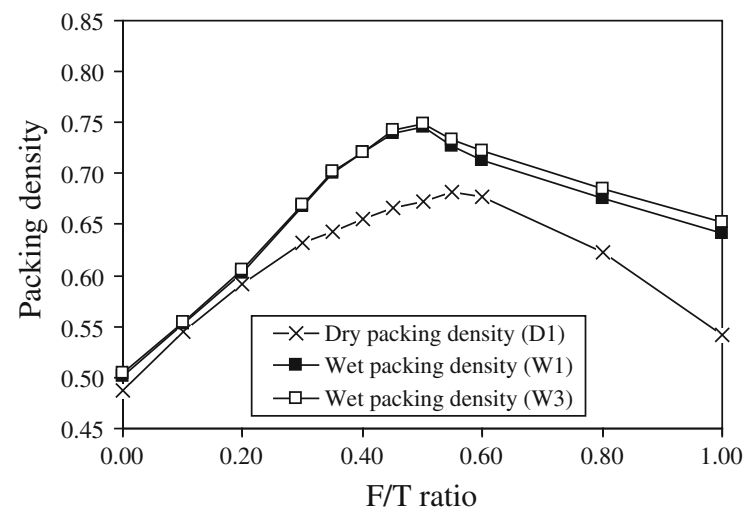

Fig. 3 Packing density of blended $\mathrm{F} 1+\mathrm{C} 1$ plotted against $\mathrm{F} / \mathrm{T}$ ratio

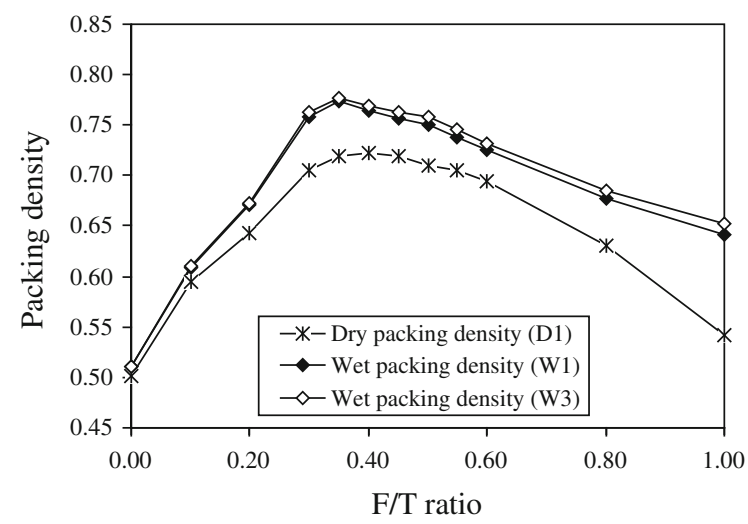

Fig. 4 Packing density of blended F1 $+\mathrm{C} 2$ plotted against F/T ratio

density was slightly lower under wet condition than dry condition.

Comparing the packing density results under the condition W3 to those under the condition W1, it can be seen that for all blended aggregate samples, regardless of the F/T ratio, the wet packing density was slightly higher with SP added. Such effect of SP may be studied in terms of the increase in packing density due to the addition of SP, as tabulated in the seventh column of Table 4. However, as can be seen from the tabulated values, the effect of SP was smaller than $2 \%$ in all cases and thus generally negligible. Since the effect of SP is dependent on the type and dosage of the SP added and the actual effect is rather small, it is suggested that for standard test of aggregate, it is better not to add any SP to avoid variations due to SP.

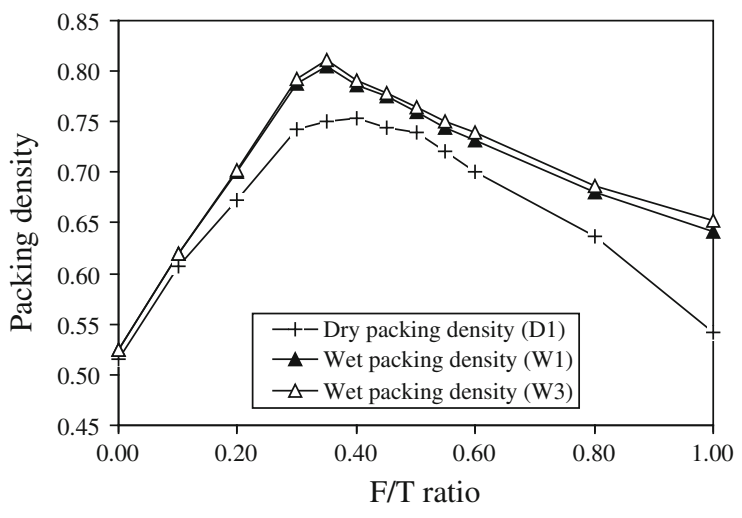

Fig. 5 Packing density of blended $\mathrm{F} 1+\mathrm{C} 3$ plotted against F/T ratio

\section{Effects of blending under dry and wet conditions}

In theory, blending of different size aggregates together so that the smaller size particles would fill into the voids between the larger size particles would increase the packing density of the aggregate. However, the increase in packing density due to blending is dependent on many factors, including the mix proportions and size ratios of the different size aggregates blended together. In this research, the opportunity was taken to study the effects of blending under dry and wet conditions.

The effects of blending F1 with $\mathrm{C} 1, \mathrm{~F} 1$ with $\mathrm{C} 2$ and F1 with $\mathrm{C} 3$ are shown in Figs. 3, 4 and 5, respectively. All the curves plotted in these figures reveal the following phenomenon. At a F/T ratio of 0 , the packing density was the same as that of the coarse aggregate. As the $\mathrm{F} / \mathrm{T}$ ratio increased, the packing density increased because the smaller size particles of the fine aggregate were filling into the voids between the larger size particles of the coarse aggregate (this is called filling effect). However, after reaching a certain optimum $\mathrm{F} / \mathrm{T}$ ratio, the packing density stopped increasing and started to decrease as the $\mathrm{F} / \mathrm{T}$ ratio further increased. This was because beyond the optimum $\mathrm{F} / \mathrm{T}$ ratio, the amount of fine aggregate added was more than sufficient to fill up the voids in the coarse aggregate causing the particles of the coarse aggregate to be pushed apart to attain a lower solid concentration. Nevertheless, the packing density of the blended aggregate was still higher than that of the fine aggregate and that of the coarse aggregate. This was because although the particles of the coarse aggregate were pushed apart 
to attain a lower solid concentration, they were still contributing to an increase in packing density by occupying solid volumes in the porous bulk volume of the fine aggregate (this is called occupying effect). Finally, as the F/T ratio increased to 1 , the packing density of the blended aggregate decreased to become the same as that of the fine aggregate. A full account of this phenomenon has been given by De Larrard [11].

It is noteworthy from the present results that the increase in packing density due to blending revealed by the dry packing tests and the corresponding increase revealed by the wet packing tests are not quite the same. The dry packing tests revealed that by blending F1 with $\mathrm{C} 1, \mathrm{~F} 1$ with $\mathrm{C} 2$ and F1 with $\mathrm{C} 3$, the packing density could be increased by $40.0 \%$ from 0.487 to 0.682 , by $44.3 \%$ from 0.501 to 0.723 , and by $46.4 \%$ from 0.515 to 0.754 , respectively. However, the wet packing tests revealed that by blending F1 with $\mathrm{C} 1, \mathrm{~F} 1$ with $\mathrm{C} 2$ and $\mathrm{F} 1$ with $\mathrm{C} 3$, the packing density could be increased by $48.4 \%$ from 0.502 to 0.745 , by $51.6 \%$ from 0.510 to 0.773 , and by $53.6 \%$ from 0.524 to 0.805 , respectively. In general, the packing density improvement is larger under wet condition than dry condition. As a fresh concrete mix is actually wet, the full potential of blending for packing density improvement is better revealed by the wet packing tests than the dry packing tests.

It should be also noted that the optimum $\mathrm{F} / \mathrm{T}$ ratio for maximum packing density revealed by the dry packing tests was generally larger than the corresponding optimum $\mathrm{F} / \mathrm{T}$ ratio revealed by the wet packing tests. The dry packing tests revealed that the optimum $\mathrm{F} / \mathrm{T}$ ratios for the $\mathrm{F} 1+\mathrm{C} 1, \mathrm{~F} 1+\mathrm{C} 2$ and $\mathrm{F} 1+\mathrm{C} 3$ blends were $0.55,0.40$ and 0.40 , respectively, whereas the wet packing tests revealed that the optimum $\mathrm{F} / \mathrm{T}$ ratios for the $\mathrm{F} 1+\mathrm{C} 1, \mathrm{~F} 1+\mathrm{C} 2$ and $\mathrm{F} 1+\mathrm{C} 3$ blends were $0.50,0.35$ and 0.35 , respectively. Hence, under wet condition, a smaller amount of fine aggregate is needed to achieve maximum packing density. This may be explained in terms of the role played by the water, which lubricates the particles, especially those of the fine aggregate, so that the fine aggregate can fill better into the voids in the coarse aggregate.

To study the effect of size ratio on the packing density of blended aggregate, the packing density results of all aggregate samples under the dry condition D1 and the wet condition W1 are plotted in Fig. 6.

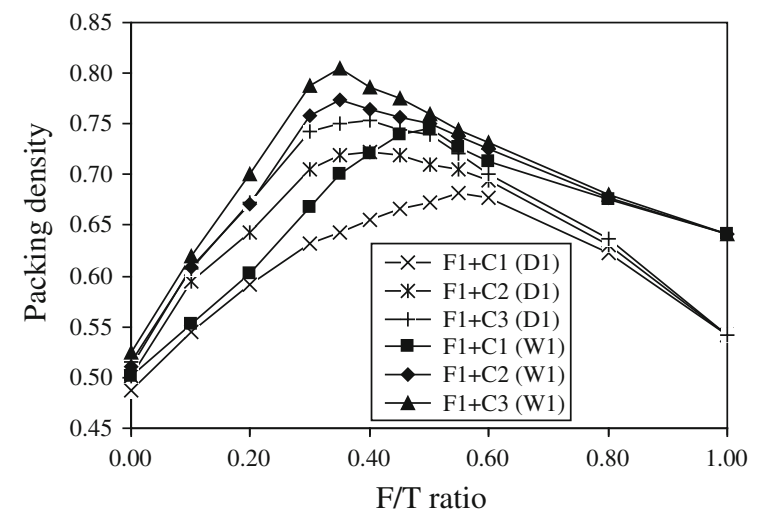

Fig. 6 Packing densities of all blended aggregates under conditions D1 and W1

Herein, the size ratio is taken as the ratio of the mean particle size of the finer aggregate to that of the coarser aggregate. For the $\mathrm{F} 1+\mathrm{C} 1, \mathrm{~F} 1+\mathrm{C} 2$ and $\mathrm{F} 1+\mathrm{C} 3$ blends, the size ratios are $0.044,0.026$ and 0.019 , respectively. From Fig. 6, it can be seen that under the same dry or wet condition, the packing density curve of $\mathrm{F} 1+\mathrm{C} 2$ is always higher than that of $\mathrm{F} 1+\mathrm{C} 1$ whereas the packing density curve of $\mathrm{F} 1+\mathrm{C} 3$ is always higher than that of $\mathrm{F} 1+\mathrm{C} 2$. This indicated that under the same dry or wet condition and at the same F/T ratio, the packing density always increased in the order of $\mathrm{F} 1+\mathrm{C} 1$ to $\mathrm{F} 1+\mathrm{C} 2$ to $\mathrm{F} 1+\mathrm{C} 3$.

The above observation may be explained in terms of the loosening effect of the fine aggregate and the wall effect of the coarse aggregate. While the fine aggregate fills into the voids of the coarse aggregate to increase packing density, the finite size of the fine aggregate may not fit well into the voids thus loosening the coarse aggregate (this is called loosening effect). On the other hand, while the coarse aggregate occupies solid volumes to increase packing density, the porosity of the fine aggregate near the coarse aggregate surfaces tends to increase thus reducing the solid concentration of the fine aggregate there (this is called wall effect). As explained by De Larrard [11], both the loosening and wall effects are generally smaller at smaller size ratio and larger at larger size ratio. Hence, a smaller size ratio would lead to larger beneficial effect of blending whereas a larger size ratio would lead to smaller beneficial effect of blending. This agrees with the general observation that a larger size range would yield a higher packing density. 


\section{Conclusions}

In order to measure the packing density of blended fine and coarse aggregate under wet condition (the actual condition in fresh concrete), the wet packing method recently developed by the authors' research team has been extended for application to blended aggregate. This extended method mixes the aggregate particles with water, measures the solid concentration of the aggregate-water mixture formed at varying water/solid ratio and determines the packing density of the aggregate as the maximum solid concentration achieved. As a part of the development process, the wet packing method was compared to the dry packing method by applying both methods to non-blended and blended aggregate samples with or without compaction applied and with or without superplasticizer added.

For non-blended aggregates, the test results revealed that the water present could increase the packing density of fine aggregate by as much as $18 \%$ but would only marginally increase the packing density of coarse aggregate. The compaction applied would increase the packing densities of both fine and coarse aggregates. However, the effect of compaction on fine aggregate is smaller under wet condition than dry condition. The superplasticizer added would also increase the packing densities of both fine and coarse aggregates but the effect is generally small. For the blended fine and coarse aggregates, the test results revealed that the wet packing density is generally higher than the corresponding dry packing density, especially when the fine aggregate content is high. As for non-blended aggregate, the effect of superplasticizer on blended aggregate is generally beneficial but small.

However, the effects of blending revealed by the dry packing tests and those revealed by the wet packing tests are not quite the same. First, the increase in packing density due to blending is generally larger under wet condition than dry condition. Hence, the full potential of blending for packing density improvement is better revealed by the wet packing tests. Second, the optimum fine to total aggregate ratio for achieving maximum packing density is generally lower under wet condition than dry condition. Hence, under wet condition, a smaller amount of fine aggregate is needed to achieve maximum packing density. Nevertheless, both the dry and wet packing test results revealed that increasing the size range of the blended aggregate would significantly increase the packing density.

Lastly, it is advocated that the dry packing method should be replaced by the wet packing method for the following reasons. First, the wet condition is more realistic because fresh mortar and concrete are actually wet. Second, if so desired, the effect of superplasticizer may be incorporated. Third, the beneficial effect of blending is better revealed. Fourth, the wet packing method may be used together with that for cementitious materials [26] to measure the packing density of all the solid particles in mortar and concrete.

Acknowledgments The work described in this paper was fully supported by a grant from the Research Grants Council of the Hong Kong Special Administrative Region, China (Project No. 713309).

Open Access This article is distributed under the terms of the Creative Commons Attribution Noncommercial License which permits any noncommercial use, distribution, and reproduction in any medium, provided the original author(s) and source are credited.

\section{References}

1. Reed JS (1995) Principle of ceramics processing, 2nd edn. Wiley, New York

2. Fayed ME, Otten L (eds) (1997) Handbook of powder science and technology, 2nd edn. Chapman \& Hall, New York

3. Powers TC (1968) The properties of fresh concrete. Wiley, New York

4. De Larrard F, Sedran T (1994) Optimization of ultra-highperformance concrete by the use of a packing model. Cem Concr Res 24(6):997-1009

5. Lange F, Mörtel H, Rudert V (1997) Dense packing of cement pastes and resulting consequences on mortar properties. Cem Concr Res 27(10):1481-1488

6. Kwan AKH, Wong HHC (2008) Packing density of cementitious materials. Part 2. Packing and flow of OPC + PFA + CSF. Mater Struct 41(4):773-784

7. Sedran T, De Larrard F, Hourst F, Contamines C (1996) Mix design of self-compacting concrete. In: Bartos PJM et al (eds) Proceedings of international RILEM conference on production methods and workability of concrete, Paisley, Scotland, pp 439-450

8. Brouwers HJH, Radix HJ (2005) Self-compacting concrete: theoretical and experimental study. Cem Concr Res 35(11):2116-2136

9. Westman AER, Hugill HR (1930) The packing of particles. J Am Ceram Soc 13(10):767-779

10. Yu AB, Zou RP, Standish N (1996) Modifying the linear packing model for predicting the porosity of nonspherical particle mixtures. Ind Eng Chem Res 35(10):3730-3741

11. De Larrard F (1999) Concrete mixture proportioning: a scientific approach. E \& FN Spon, London 
12. Johansen V, Andersen PJ (1991) Particle packing and concrete properties. In: Skalny J, Mindess S (eds) Materials science of concrete II. American Ceramic Society, Westerville, $\mathrm{OH}, \mathrm{pp}$ 111-147

13. Dewar JD (1999) Computer modelling of concrete mixtures. E \& FN Spon, London

14. Wong HHC, Kwan AKH (2008) Packing density of cementitious materials: measurement and modelling. Mag Concr Res 60(3):165-175

15. Kwan AKH, Fung WWS (2009) Packing density measurement and modelling of fine aggregate and mortar. Cem Concr Compos 31(6):349-357

16. Yen KZY, Chaki TK (1992) A dynamic simulation of particle rearrangement in powder packing with realistic interactions. J Appl Phys 71(7):3164-3173

17. Latham JP, Munjiza A, Lu Y (2002) On the prediction of void porosity and packing of rock particulates. Powder Technol 125(1):10-27

18. Fu G, Dekelbab W (2003) 3-D random packing of polydisperse particles and concrete aggregate grading. Powder Technol 133(1-3):147-155

19. Norme Belge (1981) NBN B11-206 Essais des granulats pour béton: Détermination de la masse volumique en vrac. Belgische Norm, Brussels

20. British Standards Institution (1995) BS 812 testing aggregates. Part 2. Methods of determination of density. BSI, London

21. Comité Européen de Normalisation (1998) EN 1097-3 tests for mechanical and physical properties of aggregates. Part 3. Determination of loose bulk density and voids. CEN, Brussels
22. Comité Européen de Normalisation (1999) EN 1097-4 tests for mechanical and physical properties of aggregates. Part 4 . Determination of the voids of dry compacted filler. CEN, Brussels

23. Svarovsky L (1987) Powder testing guide: methods of measuring the physical properties of bulk powders. Elsevier Applied Science Publishers Ltd, London

24. Yu AB, Bridgwater J, Burbidge A (1997) On the modeling of the packing of fine particles. Powder Technol 92(3): 185-194

25. Yu AB, Feng CL, Zou RP, Yang RY (2003) On the relationship between porosity and interparticle forces. Powder Technol 130(1-3):70-76

26. Wong HHC, Kwan AKH (2008) Packing density of cementitious materials. Part 1. Measurement using a wet packing method. Mater Struct 41(4):689-701

27. Kwan AKH, Wong HHC (2008) Effects of packing density, excess water and solid surface area on flowability of cement paste. Adv Cem Res 20(1):1-11

28. Wong HHC, Kwan AKH (2008) Rheology of cement paste: role of excess water to solid surface area ratio. J Mater Civ Eng 20(2):189-197

29. Fung WWS, Kwan AKH, Wong HHC (2009) Wet packing of crushed rock fine aggregate. Mater Struct 42(5):631-643

30. Kwan AKH, Fung WWS, Wong HHC (2010) Water film thickness, flowability and rheology of cement-sand mortar. Adv Cem Res 22(1):3-14

31. Fung WWS, Kwan AKH (2010) Role of water film thickness in rheology of CSF mortar. Cem Concr Compos 32(4):255-264 